\title{
Stakeholder and Public Participation in Water Quality Management: Case Study of University of Nottingham Malaysia Campus (UNMC) Lake
}

\author{
Doris Ifeoma Ogueri \\ University of Nottingham Malaysia Campus, Semenyih, Malaysia \\ Email: doris_duru@yahoo.com
}

How to cite this paper: Ogueri, D.I. (2018) Stakeholder and Public Participation in Water Quality Management: Case Study of University of Nottingham Malaysia Campus (UNMC) Lake. Open Access Library Journal, 5: e4423.

https://doi.org/10.4236/oalib.1104423

Received: February 13, 2018

Accepted: March 23, 2018

Published: March 26, 2018

Copyright $\odot 2018$ by author and Open Access Library Inc.

This work is licensed under the Creative Commons Attribution International License (CC BY 4.0).

http://creativecommons.org/licenses/by/4.0/

\begin{abstract}
Most urban/artificial lakes are created for relaxation, beautification and other recreational purposes. It is a way of bringing nature closer to the urban populace and lakes with better water quality contribute to a higher quality of life. Lake is an identity for all the three University of Nottingham Campuses in UK, China and Malaysia. Beautiful pictures showing the lake with the Trent building are mostly used in all marketing materials such as brochures, online marketing, hand bills and others. Due to its strategic location (entrance) and its major role in the promotion of the school's image, awareness has been drawn by various stakeholders on the degradation of University of Nottingham Malaysia Campus lake water clarity and quality. In restoring a degraded lake, it is vital to consider the interest of its stakeholders since the lake practically exists because of them. The current way they perceive the lake will help in identifying its problems while their future expectations should be integrated in the restoration measures. This study critically investigates the perception of various stakeholders in the management of the lake. The stakeholders' current perceptions and future expectations of the lake were identified through questionnaire surveys on visitors and students carried out separately coupled with interviews with some of the top management of the Campus. $70 \%$ of the total respondents (40 visitors) strongly agreed while $24 \%$ agreed that UNMC Lake enhances the landscape while the remaining $5 \%$ were neutral. 162 out of 250 students support the future use of the lake for picnics. Nature reserve and boating are other uses with high levels of responses (148 and 128 respectively). All the findings were integrated to determine the best management approach for the lake.
\end{abstract}

\section{Subject Areas}

Environmental Sciences 


\section{Keywords}

Water Quality, Management Approach, Public Perception, Lake Restoration, Stakeholders' Participation, University of Nottingham Malaysia Campus, UNMC

\section{Introduction}

[1] defined restoration as "the return of an ecosystem to a close approximation of its condition prior to disturbance". Hence, there is necessity to have the knowledge of the past condition of the ecosystem for interpretation of set environmental standards. Integrated management approach has been determined to be the best solution method for water shed problems [2]. Lakes differ a lot due to their chemical, biological and physical characteristics which are greatly dependent on their origin, watershed nature and uses. For these reasons, their problems vary and the restoration method being applied must be based on a case-by-case basis to achieve realistic results [3], [4]. It is the sole responsibility of the lake managers to carry out baseline studies on the lake in order to define its present problems and consequently implement the restoration method which will best fit the requirements of individual lakes [5]. Effective restoration plan of lake water quality involves integration of different approaches of which public perception and expectation of the lake is an important part; it is very necessary to balance the need of the community and restoration goals. In restoring a degraded lake, it is vital to consider the interest of its stakeholders since the lake practically exists because of them. The current way they perceive the lake will help in identifying its problems while their future expectations would be integrated into the restoration measures [6].

Effective restoration plan involves integration of different approaches of which public perception and expectation of the lake is an important part; it is very necessary to balance the need of the community and restoration goals. A study by [6] on management of Minnesota lakes indicated the importance of public participation in lake management which emphasized that lake management programs require public support to be successful by making sure that they have opportunity to affect the design and implementation of the program. The public's perception of present condition and future expectation of the particular lake for study should be determined because they play a central role in the future direction of lakes as they are mostly the end users.

\section{Objective and significance of study}

The iconic University of Nottingham Malaysia Campus (UNMC) Lake is an identity for all the three campuses (United Kingdom, China and Malaysia) whose major role is for promotion of the campus image. Beautiful pictures showing the lake with the Trent building are mostly used in all marketing mate- 
rials such as brochures, online marketing, hand bills and others. The magnificent view of the lake especially the night reflection brings out the real beauty of the lake. But recently, the lake has not been in its best form thereby becoming less attractive to the users.

In the light of the aforementioned reason, this study emerges to determine the importance of public and stakeholders' participation in managing the lake. The students, staff, management and the visitors are the major users of the school lake and it is very vital to hear from them on how they perceive the present condition of the lake and what they expect it to look like in the future

\section{Methodology}

The perception and future expectation of the stake holders of UNMC which include visitors, prospective students, current students and top management were obtained using different approaches. The perception of prospective students and visitors on the lake was obtained using questionnaire survey method which was administered during an open day while an online questionnaire was sent to the current students to attract higher number of respondents. Proper measures were put in place during the design of the questionnaires for clarity and easy understanding to the respondents. Simple and only relevant questions were asked to attract higher number of respondents. In addition, both structured (with options) and un-structured (open-ended) questions were used in both questionnaires in order to get the respondents' original thoughts in some questions. A clear introduction of purpose of the survey and instructions were given at the beginning of each questionnaire for guide and easy understanding. Respondents' anonymity was protected while avoiding direct and controversial questions for ethical reasons.

Some of the top management who are part of decision making body on the campus were interviewed separately. The purpose of the interview and why the interviewees were selected were described in a mail and forwarded to all of them and the interview dates and times were subsequently scheduled. The respective interviews were held in their personal offices in a friendly environment which facilitated the flow of detailed responses. The interview style described by [7] was followed. There was no general question list rather questions pertaining to each interviewee's office and relevance for the study were designed and asked separately. Permission for audio recording was obtained from all interviewees before commencement of interview. Probing method was used to get clearer and more in-depth responses to the questions.

\section{Questionnaires' Design and Delivery}

Proper measures were put in place during the design of the questionnaires to make sure that it came out clearer and easily understandable to the various respondents. The questionnaires were kept as simple as possible with fewer but important questions to attract higher number of respondents. Both structured 
questions (with options) and unstructured questions (open-ended) were used in both questionnaires. This was so because some of the questions required the respondents' original thought. A clear introduction of the purpose of the survey and instruction were given at the beginning of each questionnaire for easy understanding. The students' questionnaires were delivered online to attract a larger number of respondents because most of the students were on summer holiday during the study period. This was to reduce the chance of generating inadequate and biased data since larger sample size minimizes margin of error and yields more precise result for study. Respondents' anonymity was protected and direct and controversial questions were avoided for ethical reasons.

\section{Results and Discussions}

\subsection{Visitors' Current Perceptions and Future Expectations of UNMC Lake}

The data from the visitors' survey shows that $70 \%$ of the total respondents ( 40 visitors) strongly agreed while $24 \%$ agreed that UNMC Lake enhances the landscape while the remaining $5 \%$ were neutral as shown in Figure 1. This shows that UNMC Lake is strongly viewed for its beautification purpose and attracts the attention of anyone that drives into the campus. Most of the visitors were on the campus for the first time but yet noticed the beauty of the lake immediately. When asked the most important features they expect on the lake, they had varieties of answers ranging from-in a declining order-clear water, more trees around the edges, seating areas, attractive fish, water birds, more vegetation and water plants (lotus and water hyacinth). This confirms that the water quality degradation of the lake is easily noticed by most people while driving into the campus.

\subsection{The Students' Current Perceptions and Future Expectations of UNMC Lake}

A total of 250 UNMC students in all levels-foundation, undergraduate and postgraduate-were asked the current uses of the lake and their responses show that beautification is the major use as shown in Figure 2. Other uses by the students in a decreasing order include the following: relaxation, nature watching, physical

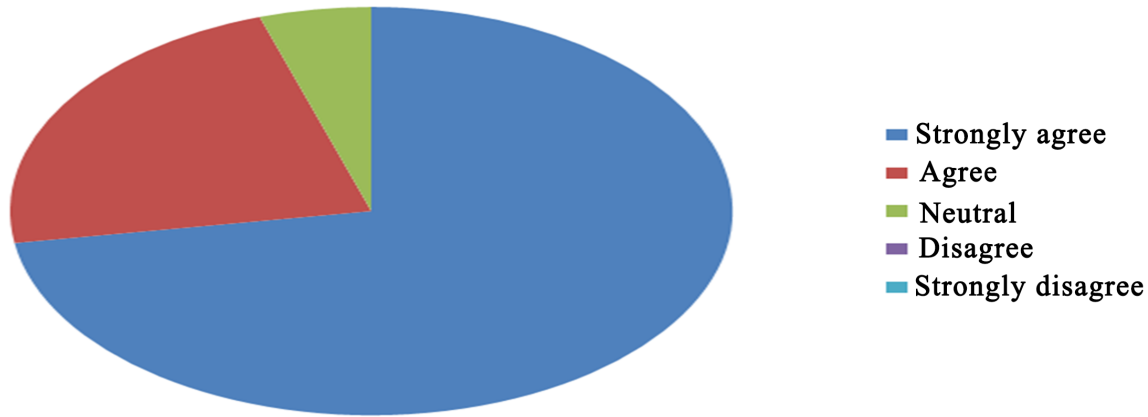

Figure 1. Visitors' perceptions of UNMC lake's landscape enhancement. 


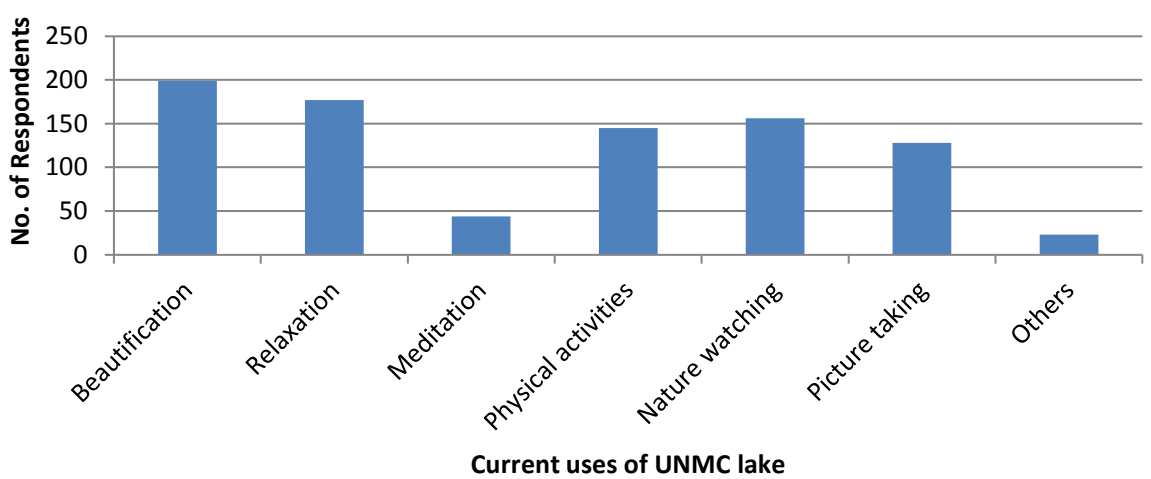

Figure 2. Students' responses on current uses of UNMC lake.

activities, picture taking, and meditation. Others specified different uses that were not provided by the researcher as research site, dating site, cooling effect on environment and storm water storage for flood control. From the students' responses, it can hence be deduced that UNMC Lake is multi-functional and deserves to be in best environmental condition always to be able to satisfy its diverse users effectively.

The students were further asked to express other ways UNMC Lake could be utilized and they provided different responses such as-water front for picnic-which got the highest response of 162 out of 250 students (Figure 3). Nature reserve and boating are other uses with high levels of responses (148 and 128 respectively). Lower number of the students also indicated they want the lake to be used for fishing, swimming and water skiing (47, 24 and 23 respectively). 180 out of 233 responses disagreed that the lake has good water clarity while greater number of students agreed that the lake is good for beautification, relaxation, physical activities and recreational purposes. They also agreed that the water fountains make the lake to be more attractive. When asked if they want all the fish in the lake to be removed, most of the students disagreed. On the comment section, some students identified some problem such as darkness on the pathway at night which affects night activities and beauty of the lake as well as narrow walkway.

The students' future expectations range from clear water, attractive fish, trees and ornamental shrubs along the shoreline and more seating areas. Others include picnic area, more water fountains, colorful lights at night, water plants (lotus, water hyacinth or lilies) and water birds (ducks and swans). In the comment box, some students identified their future expectations as; widening the pathway for easier jogging and strolling, more lighting on the pathway to enhance night beauty and activities, getting rid of the red ants on the shoreline, more wildlife and removal of the stray dogs around the lake.

Since students are part of the major stakeholders of UNMC Lake, identifying their current perception and future expectations is a major step in achieving the restoration measures for the lake. These results would then be fully integrated in the restoration plan. 


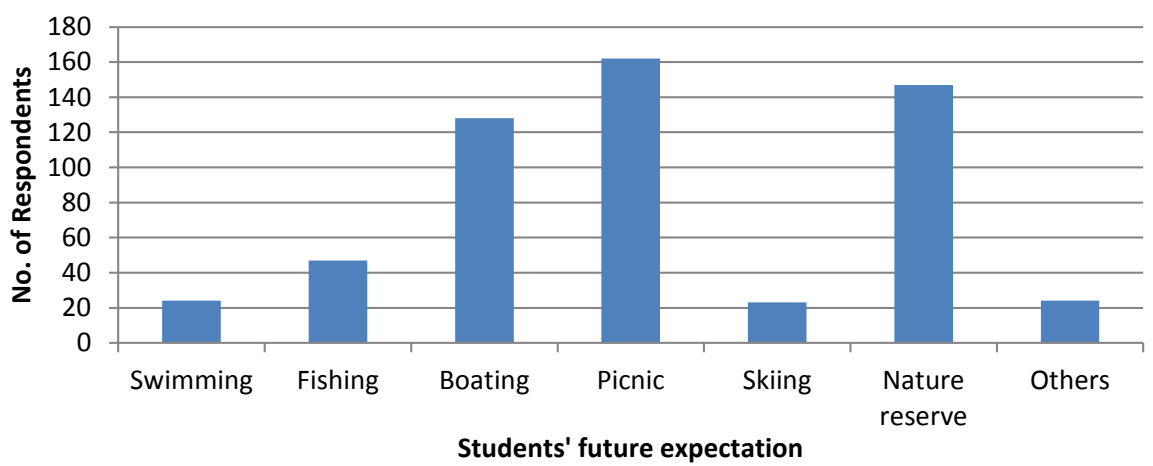

Figure 3. The future expectation of the students on the uses of the lake.

\subsection{Management Approach}

It was revealed from the marketing department that the lake is an identity for all the three university campuses (UK, China and Malaysia), serving as a promotional tool for the campus image. Beautiful pictures showing the lake with the Trent building are mostly used in all marketing materials such as brochures, online marketing, hand bills and others. The magnificent view of the lake especially the night reflection brings out the real beauty of the lake. The department revealed they expect to see more features and recreational activities on the lake such as boating, skiing, fishing and ducks which would help improve its use for marketing function because it will be better to get different pictures of a busy lake with students/staff having fun on it.

Discussions with the Estate department which is in charge of managing the lake and its catchment revealed that contractors clean lake pathway and remove leafy and other debris from the lake water daily. They also identified runoffs from the catchment as the only form of recharge for the lake; water is however drawn from the lake for watering of the lawn. This explains the low water level of the lake during the study period (summer) when there is little rain in Malaysia. It was also revealed that there is no other form of control on the discharge of runoff into the lake apart from the pollutant traps present at all the three inflows which help to filter debris from the water before draining into the lake. The traps are cleaned every 6 months. Waste water from the halls all go into the sewage treatment plant where it is treated before discharge into the public drain. The cafeteria discharge was meant to go into the sewage plant but the state of the drainage could not be ascertained. There are also 3 grease/oil traps (2 at Sodexo canteen and 1 at the block A canteen). Laboratory waste water goes into a dilution tank first and checked by the estate department before draining into the lake.

It was also observed from the interview that there is no control on the quality of the water that enters into the lake, the pollutant traps only take care of the debris but not the nutrients dissolved in the water. A lot of activities on the catchment such as fertilizer application on the soccer pitch, fogging, construction works and waste water from the halls all introduce water rich in pesticides, ferti- 
lizers, insecticides, detergents and soap which are the major sources of nutrients (phosphorus and nitrogen) that enrich the lake water. The aerators which are mainly for beautification and aeration of the lake water are not constantly on and only one is functional at present. For these aforementioned reasons, the lake water is not fully aerated which reduces the dissolved oxygen needed for aquatic organisms' growth and survival.

Discussion with the office of the provost revealed their willingness to act on the restoration measures that would be established from this study. It was found that they welcome any activities wished by the students and staff that would not contribute to noise and safety issues in the campus and also any features that would make the lake look more natural and beautiful.

\section{Conclusion}

This study was successfully carried out to identify the current perception and future expectations of the stakeholders-visitors, students, staff and management-on the campus lake. The results of this study in addition with the results of the physical and chemical analyses carried out on the lake in previous study were fully integrated into the restoration plan for the management of the lake. The final plan was presented to the campus management for further implementation. This goes a long way to show that public perception is an essential tool in effective lake water management which should not be overlooked. The stakeholders are the end users of the water bodies and their opinion or perception should not be toyed with. They deserve to be involved in any decision making process.

\section{Acknowledgements}

The researcher would like to thank Dr. Suzanne McGowan, the School of Geography and the entire University of Nottingham Malaysia Campus (UNMC) for the technical, logistics, human resource, financial and supervision support towards this study.

\section{References}

[1] Lowe, E.F., Battoe, L.E., Coveny, M.F. and Stites, D. (1999) Setting Water Quality Goals for Restoration of Lake Apokai: Interferring Past Conditions. Lake and Reservoir Management, 15, 103-120. https://doi.org/10.1080/07438149909353955

[2] Hayes, K. (2018) Integration Is the Solution: Ontario's Integrated Watershed-Based Approach for Managing Natural Resources.

http://ijc.org/greatlakesconnection/en/2018/03/integration-is-the-solution-ontariosintegrated-watershed-based-approach-for-managing-natural-resources/

[3] Ogueri, D.I. and Gumsuri, M.S. (2016) Water Quality Characterisation and Restoration Measures of University of Nottingham Malaysia Campus (UNMC) Lake. Journal of Environmental Protection, 7, 481-489. https://doi.org/10.4236/jep.2016.74042

[4] Ashraf, M.A., Maah, M.J. and Yusoff, J. (2010) Water Quality Characterization of Varsity Lake, University of Malaya, Kuala Lumpur, Malaysia. E-Journal of Chemi- 
stry, 7, S245-S254. https://doi.org/10.1155/2010/396215

[5] United States Environmental Protection Agency (1973) Measures for the Restoration and Enhancement of Quality of Freshwater Lakes.

[6] Keith, A.A., Timothy, J.K., Ronald, M.S., Hagley, C.A., Jensen, D.A. and Kreag, G.M. (1998) Public Perceptions of the Impacts, Use, and Future of Minnesota Lakes. Results of the 1998 Minnesota Lakes Survey.

[7] Boyce, C. and Neal, P. (2006) Conducting In-Depth Interviews: A Guide for Designing and Conducting In-Depth Interviews for Evaluation Input. Pathfinder International Tool Series. Monitoring and Evaluation-2. 